Научная статья

УДК 316.4

DOI: $10.18101 / 1994-0866-2021-2-86-94$

\title{
МЕСТНОЕ САМОУПРАВЛЕНИЕ В КОНТЕКСТЕ ПРОЦЕССОВ ПОЛИТОГЕНЕЗА: ИСТОРИКО-ФИЛОСОФСКОЕ РАССМОТРЕНИЕ
}

\author{
() Иваненко Игорь Николаевич \\ кандидат юридических наук, доцент, \\ доцент кафедры административного и финансового права, \\ Кубанский государственный аграрный университет имени И. Т. Трубилина \\ Россия, 350044, г. Краснодар, ул. Калинина, 13 \\ ivanenko.igor@mail.ru
}

\begin{abstract}
Аннотация. В работе рассматривается сущность государства как социальнофилософского феномена, что помогает прояснить характер процессов политогенеза с точки зрения их воздействия на историческую динамику институтов местного самоуправления. Методологическая позиция автора предполагает стык марксистской, либеральной и консервативной парадигм, каждая из которых раскрывает определенную сторону характера высшей власти. Констатируется двойственная природа государства, действия которого в той или иной степени подвержены как общенациональной детерминации, так и влиянию со стороны правящего класса. Автор заключает, что феномен государства обладает определенной внутренней противоречивостью. С одной стороны, «властный инстинкт», присущий любым государственным институтам, побуждает их стремиться распространять контроль «сверху» на все общественные отношения, с другой стороны, жизненная необходимость так или иначе заставляет умалять эти стремления, накладывая на них определенные рамки. Последнее в полной мере характеризует ситуацию с местным самоуправлением.

Ключевые слова: государство, местное самоуправление, политогенез, концепция структурации, марксистская парадигма, либеральная парадигма, консервативная парадигма, национальные интересы, классовые интересы, «властный инстинкт», суверенитет
\end{abstract}

\section{Для цитирования}

Иваненко И. Н. Местное самоуправление в контексте процессов политогенеза: историко-философское рассмотрение // Вестник Бурятского государственного университета. Философия. 2021. Вып. 2. С. 86-94.

Местное самоуправление является одним из наиболее неопределенных и проблематичных феноменов, которые весьма трудно рассматривать с точки зрения универсальных социальных принципов. Ведь даже международный документ Европейская хартия местного самоуправления - определяется экспертами как документ, отличающийся неопределенностью [19]. Между тем здесь речь идет о национальных системах, относящихся к одному западному цивилизационному типу. Уже в девятнадцатом столетии один из первых отечественных исследователей феномена местного самоуправления князь А. Васильчиков предпочитал дифференцированно подходить к проблематике принципов реализации власти «на местах» у европейских народов [3]. 
И. Н. Иваненко. Местное самоуправление в контексте процессов политогенеза: историкофилософское рассмотрение

Для России проблематика местного самоуправления выглядит весьма актуальной особенно сейчас — в период еще не закончившейся социальнополитической трансформации. Владимир Путин уже в Послании Федеральному собранию 2002 г. указывал на местное самоуправление как на один из главных приоритетов политики государства, считая местные властные институты важным фактором повышения работоспособности публичной власти ${ }^{1}$. Однако реализация Федерального Закона 131 «Об общих принципах организации местного самоуправления в Российской Федерации» (2003) серьезно пробуксовывает. На сегодняшний момент можно говорить только о фрагментарных успехах его реализации [15].

Анализ круга основных причин не очень удачного хода реформы отечественного местного самоуправления требует объема как минимум монографии. Здесь мы намерены затронуть какой-то определенный аспект, относящийся к упомянутой проблематике, рассмотрев его более или менее углубленно. Государство однозначно выступает одним из важнейших условий формирования и развития институтов местной власти, что происходит при любом типе политического режима. Тем самым государственное участие должно быть отнесено к универсальным факторам динамики местного самоуправления. Общее значение высшей власти в лаконичной форме выразил российский политолог В. Иванов, утверждая, что в том числе наиболее централизованные и «тотальные» государства допускают и даже культивируют территориальное, корпоративное самоуправление хотя бы в минимальных пределах [10, с. 14]. В то же время следует принять во внимание многозначность влияния государственного фактора на протяжении истории, поскольку, например, возможности воздействия на общественные процессы средневекового государства никак не могут быть сопоставимы со средствами, находящимися в распоряжении государства современного. Еще три-четыре столетия тому назад бюрократия выступала вполне конструктивным элементом системы социального управления, а сейчас разрастающиеся административные структуры фактически превращаются в антитезис общественного развития. Отсюда вполне уместным представляется рассмотрение меняющегося характера воздействия государственного фактора в историческом ракурсе.

Динамика государственных структур выступает главной составляющей так называемого политогенеза, который определяется Л. Грининым в качестве процесса выделения и развития в обществе политической стороны как самостоятельной и частично автономной [7]. Что касается процессов развития исключительно государственных институтов, то упомянутым ученым они обозначаются термином «стейтогенез», к которому мы в дальнейшем иногда намерены обращаться. Итак, целью настоящей работы выступает рассмотрение общих исторических особенностей динамики местного самоуправления в контексте процессов политогенеза, прежде всего его государственной составляющей. Следует оговориться, что именно стейтогенез оказался основной линией политогенеза, что ста-

\footnotetext{
${ }^{1}$ Послание Федеральному Собранию Российской Федерации 18 апреля 2002 г. URL: http://kremlin.ru/events/president/transcripts/21567 (дата обращения: 10.03.2021). Текст: электронный.
} 
ло ясно только по ходу исторического процесса. Задачами, вытекающими из обозначенной цели, служат, во-первых, уточнение сущности государства как такового, что поможет в прояснении общего смысла и характера процессов политогенеза; во-вторых, рассмотрение этапов (стадий) развития государственных институтов через призму их влияния на местное самоуправление. Реализация обозначенного замысла не позволяет уложиться в рамки одной статьи, в силу чего здесь мы сконцентрируем усилия на решении первой задачи, тогда как вторая задача будет служить предметом уже следующей статьи, соответственно являющейся логическим продолжением этой.

Говоря об источниках методологической базы нашего небольшого исследования, следует подчеркнуть следующее. Что касается сущности государства, то здесь мы предпочитаем стык марксистской, либеральной и консервативной парадигм, каждая из которых раскрывает определенную сторону миссии высшей власти. Понятие «властный инстинкт» было предложено проницательным французским исследователем А. Токвилем, и его развитие в трудах современных ученых (Ю. Хабермаса, В. Иванова, Э. Гидденса) в той или иной степени отражено в категории суверенитета. Что касается диалектического взаимодействия государства и общества по ходу истории, то его перипетии удачно раскрываются в работах ученых, предпочитающих расширенное видение возникновения и развития государственных институтов, с учетом исторических, политических, собственно социальных, а также антропологических аспектов. В первую очередь это труды Л. Гринина, во многом результирующие исследования его российских коллег Н. Крадина, А. Каратаева, Д. Бондаренко, а также некоторых зарубежных ученых - Р. Карнейро, Дж. Классена, П. Скальника и др. ${ }^{1}$ Весьма удачным дополнением к пониманию диалектики взаимоотношений государства и общества служит предложенная Э. Гидденсом концепция структурации, предполагающая «двойную включенность» индивидов и социальных структур. С одной стороны, институты создаются индивидуальными действиями, а с другой - эти же институты оказывают обратное воздействие на создавших их людей. По словам названного ученого, «структуральные свойства социальной системы выступают и как средства производства социальной жизни в качестве продолжающейся деятельности, и одновременно как результаты, производимые этой деятельностью» $[5$, c. 70$]$.

В силу того, что стержнем нашего исследования выступает рассмотрение эволюционных механизмов взаимодействий общества и государства, следует остановиться на проблематике рабочих дефиниций. В рамках обществознания встречаются различные трактовки природы государства, во многом связанные с его оценочными интерпретациями. Наша собственная позиция исходит из попыток некоего методологического синтеза противоположных интерпретаций государства, имеющихся в традиции обществознания.

Первая пара таких противоположностей касается понимания государства как части общества или, наоборот, всячески антагонистичных друг другу сущностей.

\footnotetext{
${ }^{1}$ Раннее государство, его альтернативы, аналоги: сборник статей. Волгоград: Учитель,
} 2006. $560 \mathrm{c}$. 
И. Н. Иваненко. Местное самоуправление в контексте процессов политогенеза: историкофилософское рассмотрение

Античная мысль не была склонна как-то принципиально разделять общество и государство. В известном аристотелевском концепте: человек есть политическое животное, акцент ставится на слитности фактической нераздельности в личностных рамках политического (государственного) и общественного. А вот эпоха Просвещения по сути впервые жестко поставила вопрос о возможном противостоянии абсолютистского государства гражданскому обществу. В некотором роде подобный антагонизм теоретически решался через концепцию общественного договора, где наблюдается стремление к предельной рационализации человеческого поведения, распространяющегося и на сферу политического. Забегая немного вперед, отметим, что впоследствии эта интенция была по-своему развита в марксистской теории классового государства. Французский историк Ф. Гизо считал, что в какой-то момент общество перестает нуждаться в старом государстве, может отказаться от него, сформировав новую политическую систему на более рационализированных основах [14, с. 111]. Схожие идеи имеются у немецкого культуролога В. Гумбольдта, видевшего в государстве сложный механизм, который представляет по отношению к обществу иную реальность [8, с. 71$]$.

Либеральным ученым решительно возражали сторонники государства, которых принято относить к консервативной политико-философской парадигме. Так, Г. Гегель, по сути развивая аристотелевскую традицию, подчеркивал, что любой гражданин так или иначе пропитан объективным государственным духом, задающим рамки в том числе и его морально-нравственным устоям [4, с. 279]. Российский религиозный философ Н. Бердяев явно усматривает метафизическую сущность государства, подчеркивая мистическую основу ее власти, далеко выходящую за рамки рационального понимания. «Покорность масс всякой государственной власти есть всегда безумие, есть состояние гипноза, есть трепетание народа перед реальностями, превышающими эмпирическую жизнь людей» [2, с. 528]. Государственное начало противостоит хаотическому, и хотя государства рождались на войнах и насилии, все же в противном случае человеческую цивилизацию захлестнули бы волны первоначального хаоса, тьмы и дикости» [2, с. 536].

В схожем, но несколько более приземленном ключе рассуждает современник Бердяева, философ-евразиец Н. Алексеев. По его мнению, понятие государства обозначает «властно организованную и централизованную стихию общественной жизни, общество же - неорганизованную, свободную сферу людского общения». По сути, общество в трактовке Н. Алексеева представляет собой конгломерат частных интересов, в то время как государство исходит из коллективной организации, проводя в жизнь, пусть и нередко принудительно, общие цели и интересы [1, с. 401].

На наш взгляд, и либеральный, и консервативный подходы не выходят за рамки метафизического толкования, между тем как диалектический подход к государству куда более удачно ложится в ракурс исторической динамики, которую в рамках нашего исследования мы обязаны принимать в расчет. Весьма заслуживает внимания диалектика государства, представленная марксизмом. Согласно его последователям, государство есть политическая надстройка над 
экономическим базисом, выступая продуктом социальных противоречий. Конкретная общественно-экономическая формация предопределяет лидерство определенного социального класса, который и формирует удобную ему государственную структуру, разрабатывая и навязывая необходимые сюжеты для ее легитимации. Государственные формы соответственно меняются по ходу смены формаций и новых классов-лидеров. Так, монархия являлась более адекватной для отражения феодального господства, тогда как власть капиталистов более удачно выражается формой буржуазной республики. Согласно марксистским теоретикам, государство есть отражение именно внутренней групповой борьбы и в случае единства общественных интересов «само себя делает излишним». Несмотря на то, что государство вышло из общества, оно ставит себя над ним и по ходу исторического процесса склоняется ко все большему отчуждению от него [22].

Данное толкование не без оснований видит в государственной политике отражение определенных групповых интересов, и все же менее абсолютизация этого феномена ведет к ее одностороннему суженному пониманию. Тот же исторический опыт, исследованный многими историософскими школами, убедительно иллюстрирует, что, кроме предложенной марксистами картины возникновения государства как аппарата насилия лидирующих групп над угнетенными, имелись и альтернативные варианты его зарождения. Например, современный и, кстати, марксистский ученый Б. Кагарлицкий на опыте древних держав Востока констатирует, что государственные структуры образуются здесь не вследствие образования социальных классов. Ведь «общественное разделение труда в какой-то форме уже существует, а оно неминуемо ведет к образованию классов, являясь исходным пунктом социального размежевания. Необходимость в разделении труда порождает и классы, и государство одновременно» [12].

Любые общественные отношения несут не только антагонистичный потенциал, но также имеют общие коллективные цели, на которые государство призвано ориентироваться. Правоведы-государственники Г. Радбрух, Э. М. Ориу констатируют, что любая социальная суть предполагает органичную заложенность принципов единства и целостности, результатом чего становится государствообразование $[11$, с. 56]. В определенных ситуациях могут объединиться вроде бы непримиримо антагонистичные социальные группы на почве тех же национальных интересов. Последние трактуются А. Задохиным как совокупность интересов личности, интересов различных социальных групп населения и интересов общества в целом [9].

Подобный подход хотя и ассоциируется в основном с консервативной парадигмой, при этом оказывается не лишенным той же диалектической подоплеки. Собственно уже у Г. Гегеля государство понималось как отражение народного (национального) духа. В трудах итальянского философа Ю. Эволы разрабатывается концепт «органичного государства», который находит сторонников в лице И. Ильина, О. Шпенглера, И. Исаева, А. Хабибулина и др. Их рассуждения отличает от марксизма приоритет духа над материей, а не наоборот. Идейный базис, основанный на духовной традиции, предопределяет хозяйственную и социальную жизнь. При этом государственная форма может 
И. Н. Иваненко. Местное самоуправление в контексте процессов политогенеза: историкофилософское рассмотрение

меняться в зависимости от эпохи и стоящих перед обществом наиболее актуальных задач [21, с. 68-69]. Впрочем, взгляд на государство как на интегрирующую сущность присущ не только консерваторам, но и теоретическим направлениям, делающим ставку на изучение общественного единения (Т. Парсонс).

Вышеизложенное подвигает к следующим предварительным заключениям. Фактически любое государство есть продукт общества, в котором не могут не отражаться основные социальные процессы, как структурно-функционального, так и конфликтного характера. В то же время теоретические интерпретации государства и общества сближаются и отдаляются в зависимости от определенных ракурсов. Например, политико-географическое рассмотрение государства почти отождествляет его с обществом, видя здесь определенную территорию с проживающим на ней населением, находящуюся под юрисдикцией конкретного политического организма, в свою очередь выступающего суверенным субъектом международного права. Но такое видение, весьма распространенное при геополитическом анализе, мало учитывает внутренние структурные процессы. Между тем именно последние составляют значительный аспект предмета нашего исследования. В этом плане более подходящим будет институциональное толкование государства, продвигаемое в работах Л. Гринина и его коллег. Здесь государство видится в качестве особой системы специальных институтов, органов и правил, обеспечивающих политическую жизнь общества; как особой организации власти и управления или, другими словами, как политической формы общества [6, с. 164].

Кроме того, мы считаем возможным поддержать точку зрения о двойственной природе государства, действия которого в той или иной степени подвержены как общенациональной детерминации, так и влиянию со стороны правящего класса [15]. Между тем подобная позиция должна быть представлена в динамическом ключе, что в неявной форме находит отражение и у последователей марксизма. Так, Ф. Энгельс признает, что все же может возникнуть ситуация, когда в случае равновесия сил борющихся классов «государственная власть на время получает известную самостоятельность», тем самым начиная выражать коллективные общественные цели [22, с. 364]. Но по ходу исторического процесса и смены ситуации для того или иного государства обычно оказывается в приоритете его классовая или национальная природа. При этом отнюдь не всегда они жестко противостоят друг другу, зачастую образуя определенное сочетание. Естественно, что в ходе политико-исторической динамики меняются принципы взаимодействия общества и государства какому-то государству удается полностью подмять под себя общество, а другое выступает лишь в виде внешней надстройки, по минимуму вмешивающейся во внутренние процессы социума.

Принципиальным дополнением к формируемой нами методологической базе служит учет особой качественной характеристики государства, которое помогает понять ряд важных исторических тенденций. Напомним, что уже А. де Токвиль констатировал в качестве исторической универсалии присущий государству особый властный инстинкт, благодаря которому происходят процессы централиза- 
ции $[18$, с. 61$]$. При этом упомянутый инстинкт приобретает в зависимости от различных факторов и обстоятельств то или иное наполнение. Современный классик социальной философии Э. Гидденс явно указывает на диалектику власти, заявляя о том, что власть не есть статическая величина, но расширяется относительно различных форм и свойств общественной системы [5, с. 356]. Но по сути универсальным является стремление государственной власти к некоей тотальности. Жизненную необходимость последней признает даже такой твердый сторонник и защитник либерализма, как Ю. Хабермас. «Суверенно лишь такое государство, - пишет он, - которое может внутри себя поддерживать спокойствие и порядок, а вовне de facto защищать свои границы. Во внутренних делах оно должно умело подавлять конкурирующие проявления силы, а в международных утверждать себя в качестве равноправного конкурента» [20, с. 201-202]. С точки зрения В. Иванова, это есть подлинное и полне логичное проявление суверенитета на практике [10, с. 28].

Нам представляется, что логика, задаваемая категорией суверенитета, предполагает нетерпимость государственной власти к проявлению альтернативных демонстраций суверенности. Отсюда отмечаемая некоторыми современными исследователями некая претензия на тотальность инициируемой государством правовой сферы [23]. Тому есть множество подтверждений из политической истории. Например, попытки основать казацкое государство Б. Хмельницким могли быть успешны только при условии сохранения полной автономии от близлежащих держав - Речи Посполитой, Московского царства и Османской империи, что было в принципе нереальным. Включение Войска Запорожского в Речь Посполитую, Россию, Турцию каждый раз естественным образом заканчивалось ликвидацией «вольностей» и ассимиляцией к господствующему порядку. Как пишет К. Петкевич, только благодаря постоянным войнам между этими державами некоторые институты казацкой автономии дожили почти до конца XVIII в. $[14$, c. $295-296]$.

В то же время государство никак не может быть и, собственно, никогда не было единственным держателем власти на собственной территории. Даже наиболее централизованные и «тотальные» государственные системы вынуждены были допускать и даже культивировать хотя бы минимальное территориальное или корпоративное самоуправление. «Суверенитет - это не монополия на власть, не монополия на принуждение, но это статус главной и высшей земной инстанции в соответствующих территориальных пределах инстанции, принимающей конечные и последние решения» [10, с. 18].

Итак, мы намерены констатировать, что феномен государства обладает определенной внутренней противоречивостью. С одной стороны, «властный инстинкт», присущий любым высшим институтам власти, побуждает к стремлению распространять контроль «сверху» на все общественные отношения, с другой стороны, жизненная необходимость так или иначе заставляет умалять эти стремления, накладывая на них определенные рамки. Последнее в полной мере характеризует ситуацию с местным самоуправлением. В то же время нельзя отрицать, что здесь имеется ряд исторических, культурных и даже пространственных особенностей, которые будут упомянуты в следующей статье. 
И. Н. Иваненко. Местное самоуправление в контексте процессов политогенеза: историкофилософское рассмотрение

Лuтература

1. Алексеев Н. Н. Русский народ и государство. Москва: Аграф, 1998. 640 с. Текст: непосредственный.

2. Бердяев Н. А. Философия неравенства. Москва: ЭКСМО-Пресс, 2000. 736 с. Текст: непосредственный.

3. Васильчиков А. О русском самоуправлении. Москва: Институт русской цивилизации, 2013. 960 с. Текст: непосредственный.

4. Гегель Г. Философия права. Москва: Мысль, 1990. 524 с. Текст: непосредственный.

5. Гидденс Э. Устроение общества: очерк теории структурации. Москва: Академический проект, 2005. 528 с. Текст: непосредственный.

6. Гринин Л. Е. Государство и исторический процесс. Эволюция государственности: от раннего государства к зрелому. Москва: КомКнига, 2007. 368 с. Текст: непосредственный.

7. Гринин Л. Е. Государство и исторический процесс: эпоха формирования государства. Москва: УРСС, 2011. 368 с. Текст: непосредственный.

8. Гумбольдт фон В. Язык и философия культуры. Москва: Прогресс, 1985. 451 с. Текст: непосредственный.

9. Задохин А. Г. Категория «национальные интересы» в российском политическом сознании // Обозреватель. 2013. № 1. С. 8-29. Текст: непосредственный.

10. Иванов В. В. Теория государства. Москва: Территория будущего, 2010. 272 с. Текст: непосредственный.

11. Исаев И. А. Солидарность как воображаемое политико-правовое состояние. Москва: Проспект, 2009. 176 с. Текст: непосредственный.

12. Кагарлицкий Б. Ю. От империй к империализму. Государство и возникновение буржуазной цивилизации. Москва: Изд. дом Высшая школа экономики, 2010. 680 с. Текст: непосредственный.

13. Кольев А. Н. Нация и государство. Теория консервативной реконструкции. Москва: Логос, 2005. 800 с. Текст: непосредственный.

14. Петкевич К. Казацкое государство // Раннее государство, его альтернативы, аналоги: сборник статей. Волгоград: Учитель, 2006. С. 280-304. Текст: непосредственный.

15. Тамбиянц Ю. Г., Шалин В. В. Сущность государства в эпоху глобализации: теория и практика // Общество: философия, история, культура. 2018. № 12(56). С. 13-18. Текст: непосредственный.

16. Тамбиянц Ю. Г. Проблематика сущности государства: социально-политическое, психологическое и антропологическое измерение // Этнос и общество в контексте межнациональных отношений: материалы всероссийской научно-практической конференции. Краснодар, 2019. С. 362-377. Текст: непосредственный.

17. Тамбиянц Ю. Г., Иваненко И. Н. Государство. Общество. Местное самоуправление. Краснодар: КубГАУ, 2019. 210 с. Текст: непосредственный.

18. Токвиль А. Старый порядок и революция. Санкт-Петербург: Алетейя, 2008. 272 с. Текст: непосредственный.

19. Туровский Р. Ф. Местное самоуправление: к организации эффективной власти // Общественные науки и современность. 2005. № 6. С. 68-79. Текст: непосредственный.

20. Хабермас Ю. Вовлечение другого. Очерки политической теории. Москва: Наука, 2001. 417 с. Текст: непосредственный.

21. Эвола Ю. Люди и руины. Москва: Профиздат, 2002. 288 с. Текст: непосредственный. 
22. Энгельс Ф. Происхождение семьи, частной собственности и государства. В связи с исследованиями Льюиса Генри Моргана // Маркс К., Энгельс Ф. Избранные произведения: в 3 томах. Москва: Политиздат, 1985. Т. 3. 639 с. Текст: непосредственный.

23. Яковлева Е. В. Современные аспекты развития философско-правового мировоззрения // Наука и инновации в современном мире: сборник научных статей / научный редактор Г. Р. Искандарова. Москва: Перо, 2019. Ч. IV. 252 с. Текст: непосредственный.

Статья поступила в редакиию 28.04.2021; одобрена после рецензирования 30.04.2021; принята к публикациии 11.05.2021.

\section{LOCAL GOVERNANCE IN THE CONTEXT OF POLITOGENESIS PROCESSES: A HISTORICAL AND PHILOSOPHICAL REVIEW}

\section{Igor N. Ivanenko}

Cand. Sci. (Law), A/Prof.,

A/Prof. of Administrative and Financial Law Department,

Trubilin Kuban State Agrarian University

13, Kalinina St., Krasnodar 350044, Russia

ivanenko.igor@mail.ru

Abstract. The article considers the essence of state as a socio-philosophical phenomenon, and clarifies the nature of politogenesis processes in terms of their impact on the historical dynamics of local government institutions. Our methodological position assumes a junction of the Marxist, liberal and conservative paradigms, each of them reveals a certain side of the essence of the supreme power. We have considered the dual nature of the state, which actions to one degree or another are subject to both national determination and the influence of the ruling class. It is concluded that the phenomenon of the state has a certain internal inconsistency. On the one hand, the "power instinct" inherent in any state institutions encourages them to extend control "from above" to all social relations, on the other hand, the vital necessity makes them belittle these aspirations, imposing certain constraints. The latter fully characterizes the situation with local governence.

Keywords: state, local governence, politogenesis, structuration concept, Marxist paradigm, liberal paradigm, conservative paradigm, national interests, class interests, "power instinct", sovereignty

For citation

Ivanenko I. N. Local Governance in the Context of Politogenesis Processes: A Historical and Philosophical Review. Bulletin of Buryat State University. Philosophy. 2021; 2: 86-94 (In Russ.).

The article was submitted 28.04.2021; approved after reviewing 30.04.2021; accepted for publication 11.05.2021. 